\title{
The Endocrine Pancreas in Pyridoxine Deficient Rats
}

\author{
Takayoshi Toyota, Yukihiro KaI, Masaei Kakizaki, \\ Hidetsugu Ohtsuka,* Yukio Shibata* and Yoshio Goto \\ The Third Department of Internal Medicine, Tohoku University \\ School of Medicine, Sendai 980 and * Department of \\ Biochemistry, Aichi Medical University, Nagakute, Aichi \\ $4 \%-11$
}

Toyota, T., KaI, Y., Kakizaki, M., Ohtsuka, H., Shibata, Y. and Goto, Y. The Endocrine Pancreas in Pyridoxine Deficient Rats. Tohoku J. exp. Med., 1981, 134 (3), 331-336 — Because the supplementation of pyridoxine (vitamin $B_{6}$ ) improves the glucose tolerance in gestational diabetes and adult onset diabetes, pyridoxine deficiency has been considered to be one of the factors that cause diabetes mellitus. We produced pyridoxine deficient rats by giving pyridoxine-free food with deoxypridoxine which inhibits competitively the activity of pyridoxal phosphate. In these pyridoxine deficient rats plasma insulin during the glucose tolerance test was significantly low as compared with controls. In vitro experiments of pancreas perfusion showed that secretion of insulin and glucagon was impaired in the pyridoxine deficiency. Since the restriction of diet-calorie caused a decrease in arginine-induced secretion of insulin and glucagon from the isolated pancreas, the impairment of the endocrine pancreas may depend on malnutrition. Pyridoxine deficiency is surely one of the factors that impair the endocrine pancreas by multifactorial derangement of metabolism besides the tryptophannicotinic acid pathway. ——insulin; pyridoxine; perfusion of isolated pancreas

As a result of dietary pyridoxine deficiency xanthurenic acid, which forms the complex with insulin and inhibits glucose uptake into fat cells, is increased (Kotake and Inada 1953a, b; Kotake et al. 1968, 1975; Kotake and Murakami 1971; Murakami and Kotake 1972). By-products from tryptophan, i.e. quinaldic acid and hydroxyquinaldic acid inhibit synthesis of proinsulin in the islet cells of rats (Noto and Okamoto 1978). In diabetic patients a large amount of xanthurenic acid is excreted into the urine (Kotake and Inada 1953a; Rosen et al. 1955). Because the supplementation of pyridoxine lowers the blood level of glucose in gestational diabetes (Schultz 1963), kynurenine metabolites, by-products of tryptophannicotinic acid metabolism, would play an etiologic role in human diabetes.

The present study was carried out to investigate the endocrine pancreas in pyridoxine deficient rats. Using in vitro perfusion experiments of the isolated pancreas, we tried to elucidate a problem that the pyridoxine deficiency could cause any deterioration in insulin and glucagon secretion.

Received for publication, October 13, 1980. 


\section{Methods and Materials}

Pyridoxine deficient rats were fed on Test Meal A which did not contain pyridoxine but deoxypyridoxine $(10 \mathrm{mg} / \mathrm{l} 00 \mathrm{~g})$. In principle, activity of pyridoxine is competitively inhibited by deoxypyridoxine.

Male albino rats of the Wistar strain were used for this study. Feeding on Test Meal A was started 5 weeks after birth. Thirty-four days after it, pyridoxine deficiency became evident. The skin dried and hair turned yellow and coarse (Group A).

Another group of rats (Group B) was given a test meal consisting of corn starch (38 $\%)$, vitamin free casein $(25 \%)$, alpha starch $(10 \%)$, cellulose $(8 \%)$, linolate salad oil $(6 \%)$, granule sugar $(5 \%)$, salt $(6 \%)$, vitamin A (1000 IU), $B_{1}(2.4 \mathrm{mg}), \mathrm{B}_{9}(8 \mathrm{mg}), \mathrm{B}_{12}(0.001 \mathrm{mg})$, $\mathrm{C}(60 \mathrm{mg}), \mathrm{D}_{2}(200 \mathrm{IU}), \mathrm{E}(10 \mathrm{mg}), \mathrm{K}_{3}(10.4 \mathrm{mg})$, biotin $(0.04 \mathrm{mg})$, niacin $(12 \mathrm{mg})$, inositol $(12 \mathrm{mg})$ and choline hydrochloride $(5 \mathrm{mg})$. These rats were furnished restricted calories so as to keep almost all the same body weight as Group A.

Control rats (Group C) were given ad libitum the conventional chow purchased from Oriental Kobe Co. Thirty-four days after the start of expəriments, body weights of the rats in Groups A, B and C were $126 \pm 5,158 \pm 8$ and $230 \pm 15 \mathrm{~g}$, respectively. After an overnight fast, the glucose tolerance test (GTT) was carried out in the three groups. Glucose solution, $2 \mathrm{~g} / \mathrm{kg}$ body weight, was given orally and blood samples were obtained from tail vessels every $30 \mathrm{~min}$ for $2 \mathrm{hr}$ for the determination of glucose and insulin.

The pancreas was isolated by the procedure described by Grodsky et al. (1963) with some modifications (Toyota et al. 1978). Under anesthesia with pentobarbital sodium, $45 \mathrm{mg} / \mathrm{kg}$ body weight, the abdominal cavity was opened. The stomach and spleen were removed without bleeding. The pancreas was isolated together with the proximal portion of the duodenum. After placed in an incubator, the pancreas was perfused with perfusion medium through a plastic cannula which had been inserted into the celiac artery. The perfusion medium was Krebs-Ringer bicarbonate buffer containing dextran $(5 \%)$ and glucose $(3.8 \mathrm{mM})$. It was gassed with a mixture of $95 \% \mathrm{O}_{2}$ and $5 \% \mathrm{CO}_{2}$, resulting in $\mathrm{pH}$ 7.4. Arterial $\mathrm{pO}_{2}$ was $300-350 \mathrm{mmHg}$ and portal $\mathrm{pO}_{2}$ was $150-200 \mathrm{mmHg}$. The approximate difference in oxygen tension across the pancreas was $100 \mathrm{mmHg}$. The flow rate was maintained constantly between 2.8 and $3.0 \mathrm{ml} / \mathrm{min}$ and the pressure was about $80 \mathrm{~mm}$ $\mathrm{Hg}$. In all experiments perfusate samples, $3 \mathrm{ml}$ each, were collected from a cannula in the portal vein at suitable intervals as indicated in Figs. 1 and 2. Immediately after sampling, the tubes containing $3 \mathrm{ml}$ of the perfusate and $0.1 \mathrm{ml}$ of aprotinin (Trasylol, Bayer, GFR) were kept at $4^{\circ} \mathrm{C}$ and stored at $-20^{\circ} \mathrm{C}$ until analysis.

A 15-min period of perfusion with Krebs-Ringer bicarbonate buffer containing 3.8 $\mathrm{mM}$ glucose was allowed before the start of the experiments. The pancreas was stimulated with $11.1 \mathrm{mM}$ glucose for $10 \mathrm{~min}$ and after a 15-min interval in the presence of $3.8 \mathrm{mM}$ glucose, the pancreas was stimulated again with arginine hydrochloride solution, $20 \mathrm{mM}$, for $10 \mathrm{~min}$.

Insulin and glucagon were measured by a charcoal separation method for radioimmunoassay. ${ }^{125}$ I-labeled pork insulin purchased from Dainabott Radioisotope Laboratory, Tokyo, and rat insulin from Novo Research Institute, Copenhagen, Denmark, were used for insulin assay. ${ }^{125}$ I-labeled pork glucagon purchased from Nuclear Medical Laboratory, Dallas, Texas, USA, and antiserum to glucagon ( $30 \mathrm{~K})$ were used for glucagon assay. Statistical comparison was performed using Student's $t$-test.

\section{RESULTS}

Pyridoxine deficient rats, Group A, were characterized by growth retardation and dermatitis. Their fasting plasma insulin was $11.6 \pm 0.8 \mu \mathrm{U} / \mathrm{ml}$ (mean \pm s.e.) which was significantly lower than $20.3 \pm 1.9 \mu \mathrm{U} / \mathrm{ml}$ of controls. Each average of plasma insulin at 30,60 and 90 min after glucose ingestion was low as compared with controls (Table 1 ). 
The pancreas isolated from the pyridoxine deficient rats responded to a continuous infusion of glucose or arginine with a monophasic pattern of insulin secretion. As shown in Fig. 1, insulin release stimulated by glucose, and especially by arginine, at intervals of $15 \mathrm{~min}$ was deteriorated remarkably in the pyridoxine deficient rats. The sum of insulin values was $14.6 \pm 5.7 \mathrm{ng} / \mathrm{ml} / 10 \mathrm{~min}$ during arginine

TABLE 1. Oral glucose tolerance test

\begin{tabular}{|c|c|c|c|c|c|}
\hline & 0 & 30 & 60 & 90 & $120 \mathrm{~min}$ \\
\hline \multicolumn{6}{|l|}{ Pyridoxine deficient rats } \\
\hline Blood glucose $(\mathrm{mg} / 100 \mathrm{ml})$ & $71 \pm 8$ & $157 \pm 15$ & $141 \pm 11$ & $99 \pm 4 \dagger$ & $92 \pm 4$ \\
\hline Plasma insulin $(\mu \mathrm{U} / \mathrm{ml})$ & $11.6 \pm 0.8 \dagger$ & $21.0 \pm 1.9^{*}$ & $13.3 \pm 1.3^{*}$ & $11.2 \pm 0.5_{\ddagger}^{\dagger}$ & $11.8 \pm 1.0$ \\
\hline \multicolumn{6}{|l|}{ Calorie-restricted rats } \\
\hline Blood glucose $(\mathrm{mg} / 100 \mathrm{ml})$ & $74 \pm 2$ & $105 \pm 2+$ & $116 \pm 3 \ddagger$ & $118 \pm 3$ & $101 \pm 4$ \\
\hline Plasma insulin $(\mu \mathrm{U} / \mathrm{ml})$ & $18.9 \pm 1.7$ & $20.6 \pm 1.1^{*}$ & $21.6 \pm 1.1$ & $17.1 \pm 1.5$ & $15.0 \pm 0.7$ \\
\hline \multicolumn{6}{|l|}{ Control rats } \\
\hline Blood glucose $(\mathrm{mg} / 100 \mathrm{ml})$ & $79 \pm 4$ & $129 \pm 2$ & $143 \pm 3$ & $118 \pm 4$ & $101 \pm 4$ \\
\hline Plasma insulin $(\mu \mathrm{U} / \mathrm{ml})$ & $20.3 \pm 1.9$ & $30.8 \pm 2.3$ & $28.4 \pm 3.1$ & $19.7 \pm 1.2$ & $17.8 \pm 1.5$ \\
\hline
\end{tabular}

$* p<0.05$, $\dagger p<0.02$, and $\ddagger p<0.01$ v.s. control.

Each value is presented as means of five experiments \pm s.e. Ratios of the sum of plasma insulin to that of blood glucose are calculated. The ratios in pyridoxine deficient rats and calorie-restricted rats are $0.135 \pm 0.009$ and $0.181 \pm 0.006$, respectively. The ratios are significantly lower than $0.203 \pm 0.015$ of normal rats $(p<0.01)$.

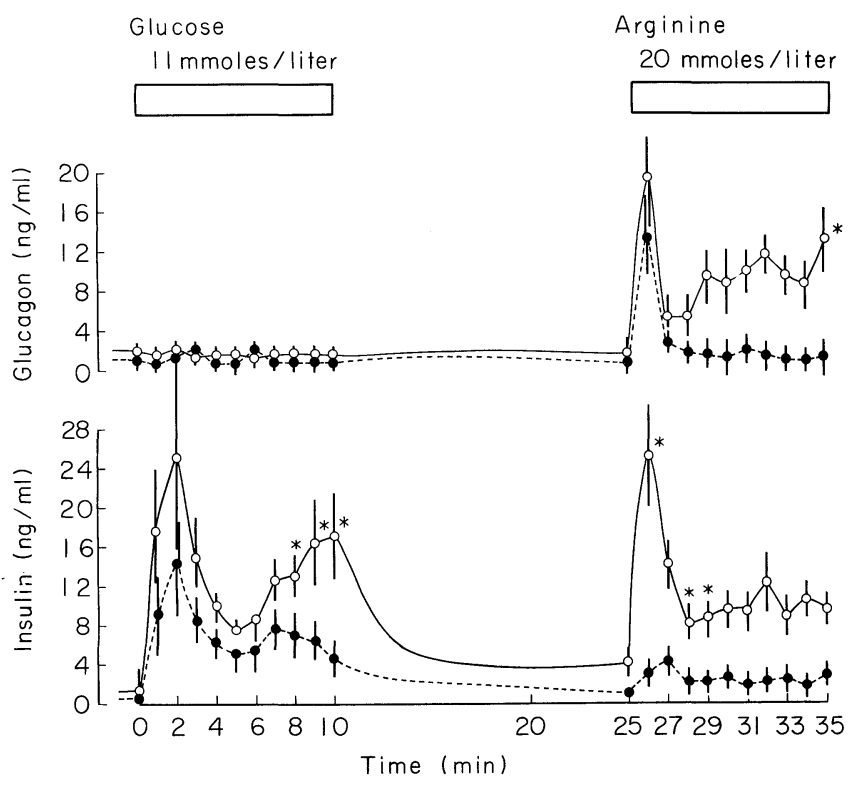

Fig. 1. Insulin and glucagon secretion from the pancreas isolated from pyridoxine deficient rats (Group A). Sums of insulin values during glucose infusion and arginine infusion are $63.8 \pm 15.4$ and $14.7 \pm 5.7 \mathrm{ng} / \mathrm{ml} / 10 \mathrm{~min}$, respectively. Controls are $131 \pm 26.5$ and $68 \pm 23.3 \mathrm{ng} / \mathrm{ml} / 10 \mathrm{~min}$ (Group C). Sum of glucagon values during arginine infusion is $24.4 \pm 9.4 \mathrm{ng} / \mathrm{ml} / 10 \mathrm{~min}$ in Group A and $84.2 \pm 16.6 \mathrm{ng} / \mathrm{ml} / 10 \mathrm{~min}$ in Group C. - $\cdots$ Group A $(n=4) ; 0 \cdots \circ$ Group C $(n=4)$. 


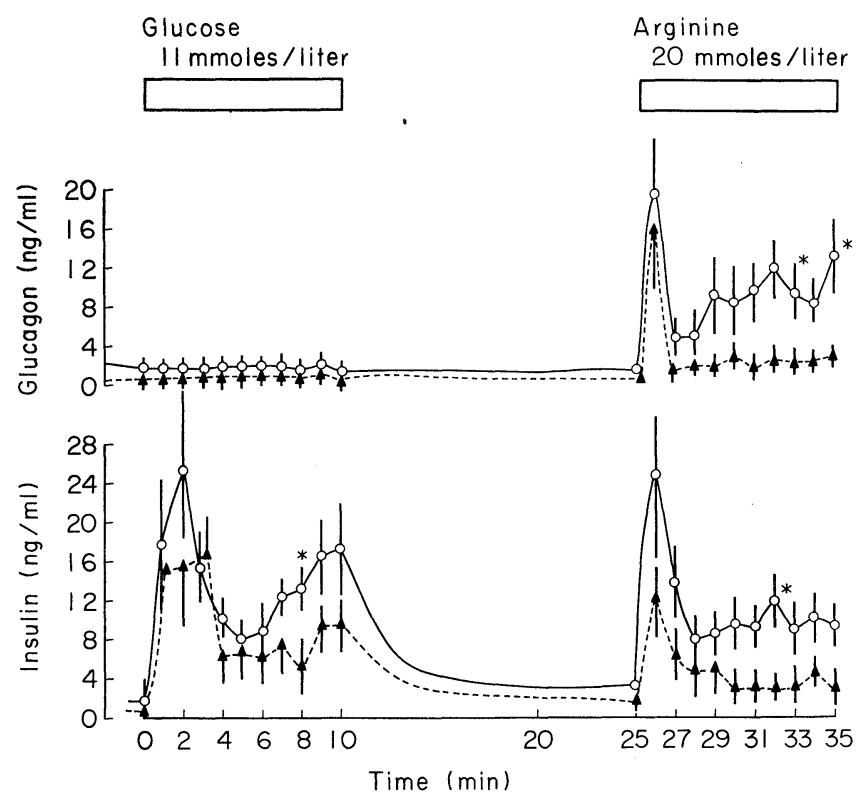

Fig. 2. Insulin and glucagon secretion from the pancreas isolated from calorie-restricted rats (Group B). Sums of insulin values during glucose infusion and arginine infusion are $90.5 \pm 13.0$ and $37.7 \pm 8.6 \mathrm{ng} / \mathrm{ml} / 10 \mathrm{~min}$, respectively. Sum of glucagon values during arginine infusion is $27.2 \pm 7.1 \mathrm{ng} / \mathrm{ml} / 10 \mathrm{~min}$. $\wedge$, Group B $(n=4)$; ○- , Group C $(n=4)$.

infusion in Group A, while the sum of insulin values was $68 \pm 23.3 \mathrm{ng} / \mathrm{ml} / 10 \mathrm{~min}$ in controls (Group C).

Glucagon release was also suppressed in the pyridoxine deficient rats. Fig. 1 shows that Group A responded to arginine infusion with a monophasic pattern of glucagon secretion as in the case of insulin. The sum of glucagon values during arginine infusion in Group A was $24.4 \pm 9.4 \mathrm{ng} / \mathrm{ml} / 10 \mathrm{~min}$ which was significantly lower than $84.2 \pm 16.6 \mathrm{ng} / \mathrm{ml} / 10 \mathrm{~min}$ in Group C. These results may imply that pyridoxine deficiency disturbs the endocrine pancreas. However, from the fact that the calorie-restricted rats (Group B) were also insufficient in the function of the endocrine pancrease (Fig. 2), we can hardly deduce the conclusion that the reduction of insulin and glucagon secretion is not due to malnutrition but due to an increase in kynurenine metabolites consequent to pyridoxine deficiency.

The present results showed that in Group B the insulin level during GTT was below the normal level. The ratio of the sum of insulin values to that of blood glucose during GTT in Group B was $0.181 \pm 0.006$ which was significantly lower than $0.203 \pm 0.015$ in Group $\mathrm{C}(p<0.01)$.

\section{Discussion}

Pyridoxine deficiency has been produced in experimental animals by administration of tryptophan rich diet, glucocorticoids and contraceptive steroid 
(Altman and Greengard 1966; Price et al. 1967; Rose and Braidman 1971). We produced pyridoxine deficient rats by giving pyridoxine-free food with deoxypyridoxine which inhibits competitively the activity of pyridoxal phosphate. In pyridoxine deficiency a large amount of xanthurenic acid is excreted in urine because the main pathway of tryptophan breakdown is blocked owing to lack of pyridoxine.

Pyridoxal phosphate (vitamin $\mathrm{B}_{6}$ ) is required as coenzyme by kynureninase which catalyzes the main pathway of kynurenine and hydroxykynurenine formed from tryptophan into anthranilic acid and hydroxyanthranilic acid, respectively (Takahashi et al. 1956; Kaihara and Price 1962; Goda et al. 1977; Shibata 1978).

Focussing our attention on the pancreatic beta cells, we are interested in the fact that quinaldic acid and hydroxyquinaldic acid inhibit insulin secretion from the pancreatic islet cells (Okamoto 1975). If pyridoxine deficiency causes an increase in quinaldic acid and hydroxyquinaldic acid, the impairment of insulin secretion would be attributed, as shown in Fig. 1, to an increase in kynurenine metabolites owing to derangement of tryptophan-nicotinic acid metabolism.

It is of interest to note that the pancreas isolated from the pyridoxine deficient rats responded to arginine infusion with a monophasic pattern of glucagon secretion as in insulin secretion and that the glucagon level was remarkably lower than that of control rats. Although there has been no available information concerning effects of kynurenine metabolites on the pancreatic alpha cells, pyridoxine deficiency possibly affects not only insulin but also glucagon secretion.

Is it true that the reason why pyridoxine deficiency inhibits the endocrine pancreas is because kynurenine metabolites are increased? Since the restriction of diet-calorie caused a decrease in the arginine-induced insulin and glucagon secretion as illustrated in Fig. 2, the impairment of the endocrine pancreas may depend on malnutrition in a broad sense. Pyridoxine deficiency is known to deteriorate not only protein but also fat metabolism, resulting in deficiency of essential fatty acid (Mueller and Iacono 1963; Huber et al. 1968).

Early clinical studies showed that the supplementation of pyridoxine improved blood glucose in gestational diabetes (Bennink and Schreurs 1975) and adult onset diabetes (Schultz 1963). However, recent works could recognize no significant alteration in the glucose tolerance in diabetic patients by the treatment with pyridoxine (Perkins 1977; Gillmer and Mazibuko 1979; Rao et al. 1980). Although pyridoxine deficiency is surely one of the factors that impair the endocrine pancreas, it is difficult to conclude that diabetic state is produced by pyridoxine deficiency alone. Further study is necessary in the future for clarifying the relationship between onset of diabetes mellitus and pyridoxine deficiency.

\section{References}

1) Altman, K. \& Greengard, O. (1966) Tryptophan pyrrolase induced in human liver by hydrocortisone on excretion of kynurenine. Science, 151, 332-333.

2) Bennink, H.J.T.C. \& Schreurs, W.H.P. (1975) Improvement of oral glucose tolerance in gestational diabetes by pyridoxine. Brit. med. J., 3, 13-15. 
3) Gillmer, M.D.G. \& Mazibuko, D. (1979) Pyridoxine treatment of chemical diabetes in pregnancy. Amer. J. Obst. Gynecol., 133, 499-502.

4) Goda, K., Ueda, T. \& Kotake, Y. (1977) Kinetic studies of the reduction of methemoglobin by 5 -hydroxyanthranilic acid, tryptophan metabolite. Biochem. biophys. Res. Comm., 78, 1198-1203.

5) Grodsky, G.M., Batt, A.A., Benett, L.L., Vcella, C., McWilliams, N.B. \& Smith, D.F. (1963) Effects of carbohydrates on secretion of insulin from isolated rat pancreas. Amer. J. Physiol., 205, 638-644.

6) Huber, A., Gershoff, S. \& Hegsted, D. (1938) Carbohydrate and fat metabolism and response to insulin in vitamin $\mathrm{B}_{6}$ deficient rats. $J$. Nutr., 82, 371-378.

7) Kaihara, M. \& Price J.M. (1962) The metabolism of quinaldic acid, kynurenic acid, xanthurenic acid in the rabbit. J. biol. Chem., 237, 1727-1729.

8) Kotake, Y. \& Inada, T. (1953a) Studies on xanthurenic acid. I. The effect of fatty acid and its relation to pyridoxine. J. Biochem., 40, 287-289.

9) Kotake, Y. \& Inada, T. (1953b) Studies on xanthurenic acid. II. Preliminary report on xanthurenic acid diabetes. J. Biochem., 40, 291-294.

10) Kotake, Y. \& Murakami, E. (1971) A possible diabetogenic role for tryptophan metabolites and effects of xanthurenic acid on insulin. Amer. J. clin. Nutr., 24, 826829.

11) Kotake, Y., Sotokawa, T., Murakami, W., Hisatake, A., Abe, M. \& Ikeda, Y. (1968) Studies on the xanthurenic acid-insulin complex. II. Physiological activities. $J$. Biochem., 63, 578-581.

12) Kotake, T., Ueda, T., Mori, T., Murakami, E. \& Hattori, M. (1975) The physiological significance of the xanthurenic acid-insulin complex. J. Biochem., 77, 685-687.

13) Mueller, J. \& Iacono, J. (1963) Effect of desoxypyridoxine-induced vitamine $B_{6}$ deficiency on polyunsaturated fatty acid metabolism in human being. Amer. J. clin. Nutr., 12, 358-366.

14) Murakami, E. \& Kotake, Y. (1972) Studies on the xanthurenic acid-insulin complex. III. Distribution of xanthurenic acid and formation of xanthurenic acid-insulin complex in serum. J. Biochem., 72, 251-259.

15) Noto, Y. \& Okamoto, H. (1978) Inhibition by kynurenine metabolites of proinsulin synthesis in isolated pancreatic islets. Acta diabetol. lat., 15, 273-281.

16) Okamoto, H. (1975) Effect of quinaldic acid and its relatives on insulin-release from isolated Langerhans islets. Acta vitaminol. enzymol., 24, 227-231.

17) Perkins, R.P. (1977) Failure of pyridoxine to improve glucose tolerance in getational diabetes mellitus. Obstet. Gynecol., 50, 370-372.

18) Price, J.M., Thornton, M.J. \& Mueller, J.M. (1967) Tryptophan metabolism in women using steroid hormones for ovulation control. Amer. J. clin. Nutr., 20, 452-456.

19) Rao, R.H., Vigg, B.L. \& Rao, K.S.J. (1980) Failure of pyridoxine to improve glucose tolerance in diabetics. J. clin. Endocr. Metab., 50, 198-200.

20) Rose, D.P. \& Braidman, I.P. (1971) Excretion of tryptophan metabolites as affected by pregnancy, contraceptive steroids and steroid hormones. Amer. J. clin. Nutr., 24, 673-683.

21) Rosen, D., M-Davis, G., Becker, B., Stone, H. \& Friedenwald, J. (1955) Xanthurenic acid excretion studies in diabetics with and without retinopathy. Proc. Soc. exp. Biol. Med. 88, 321-323.

22) Schultz, G.O. (1963) Occurrence in North Sumatra of diabetes due to pyridoxine deficiency. Int. Z. Vitaminforsch., 23, 150-154.

23) Shibata, Y. (1978) On the regulation of tryptophan metabolism via kynurenine. Acta vitaminol. enzymol., 32, 195-207.

24) Takahashi, H., Kaihara, M. \& Price, J.M. (1956) The conversion of kynurenic acid to quinaldic acid by human and rats. J. biol. Chem., 223, 705-708.

25) Toyota, T., Kakizaki, M., Kimura, K., Yajima, M., Okamoto, T. \& Ui, M. (1978) Islet activating protein (IAP) derived from the culture supernatant fluid of Bordetella pertussis: Effect of spontaneous diabetes rats. Diabetologia, 14, 319-323. 